\title{
胃X線造影画像における視営評価の要因について

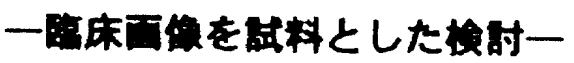

The Factor of Visual Evaluation in Upper GI Radiography

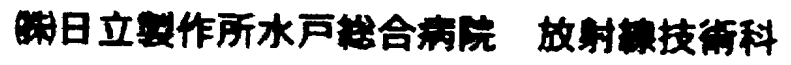

\begin{tabular}{|c|c|}
\hline $\begin{array}{l}\text { O川上茫弘 } \\
\text { (T. Kawakami) }\end{array}$ & $\begin{array}{c}\text { 宮下沽一 } \\
\text { (Y. Miyashita) }\end{array}$ \\
\hline
\end{tabular}

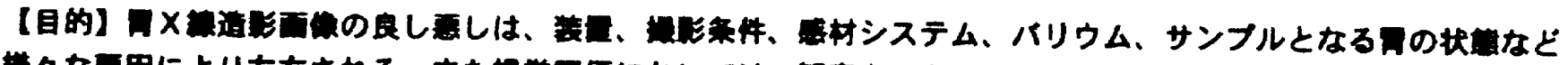

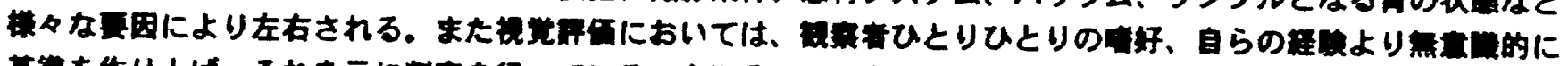

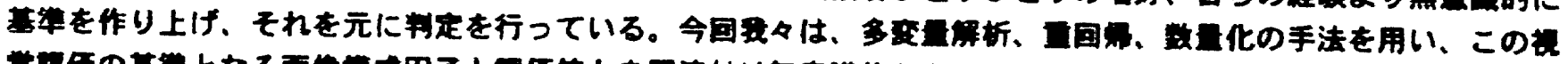

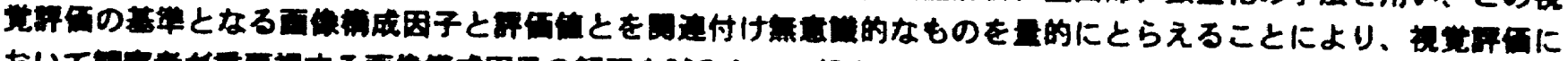

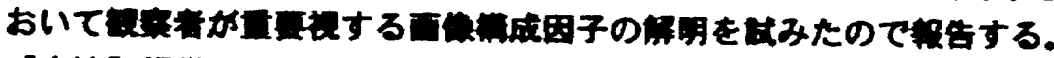

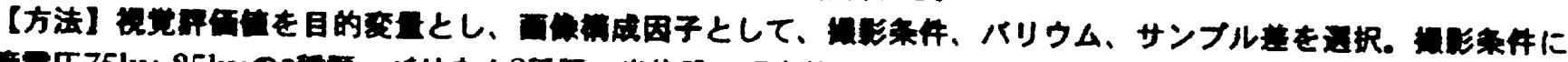

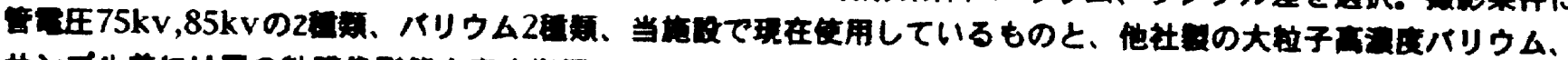

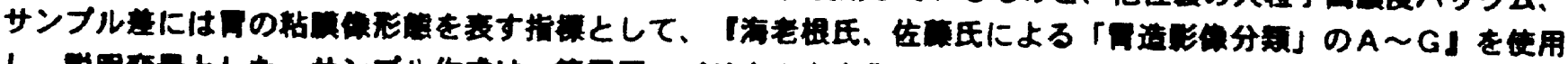

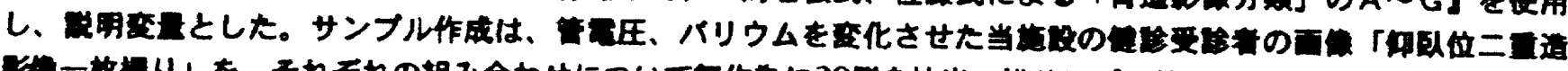

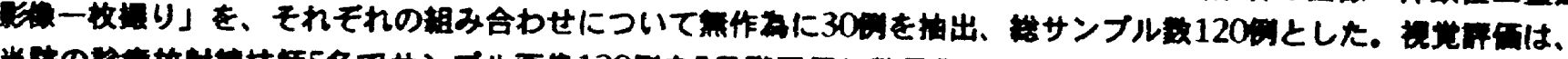

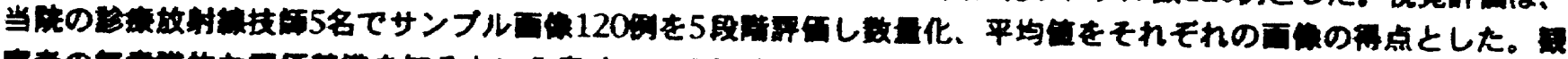

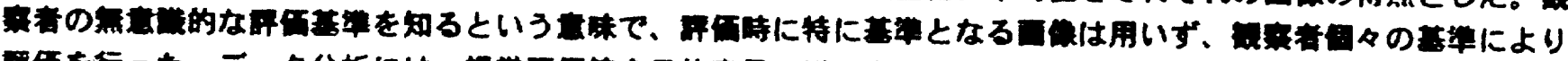

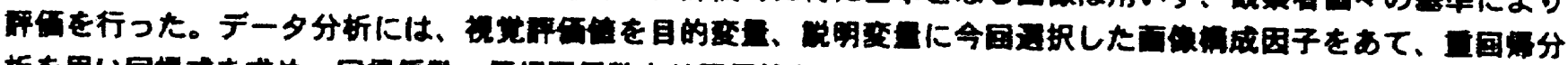

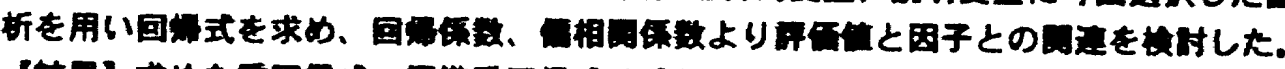

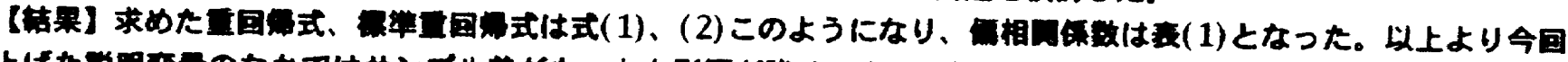

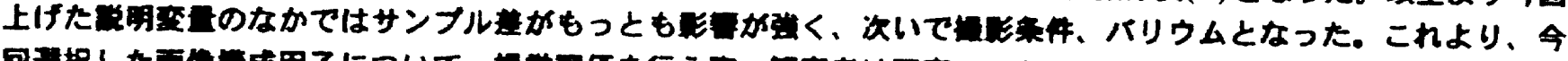

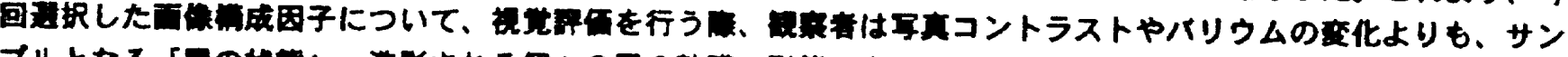

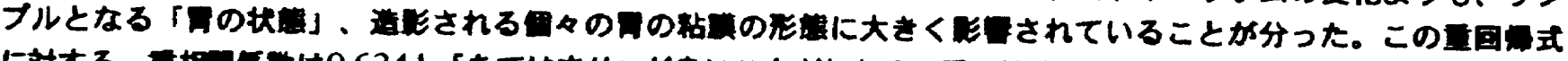

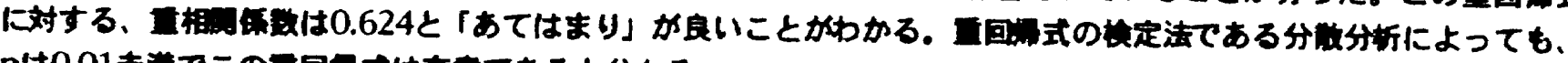
pは0.01末洋でこの国国式は有昔であると分かる。

F国我式 (Evalution) $=-0.030$ (Condition) $-0.257(\mathrm{Ba})+0.415$ (Sample) $+9.109 \cdots$

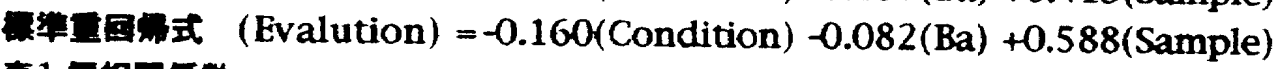

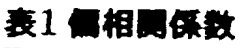

\begin{tabular}{|c|c|c|c|}
\hline & Condition & Ba & Sample \\
\hline Value & -0.201 & -0.104 & 0.600 \\
\hline
\end{tabular}

I相的 $\mathrm{R}=0.624$

分散分析 F Value $=\mathbf{2 3 . 5 6}$

p Value $<0.01$

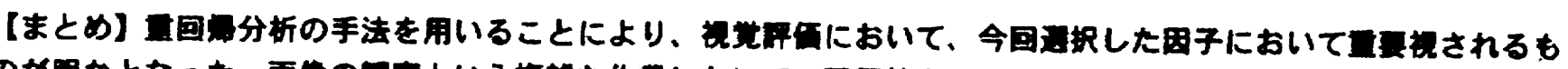

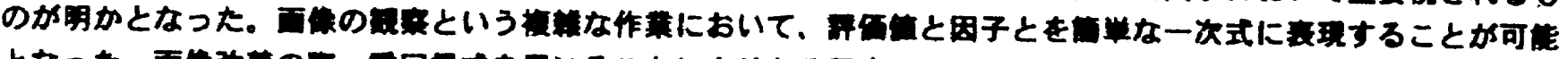

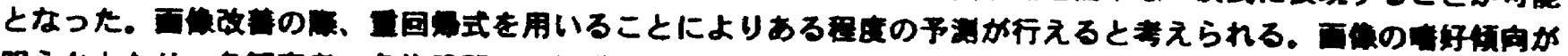

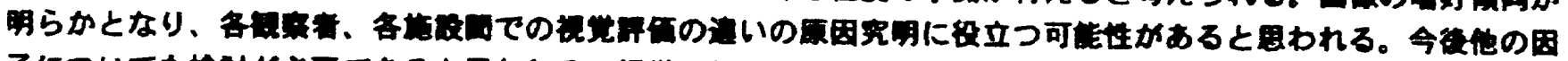

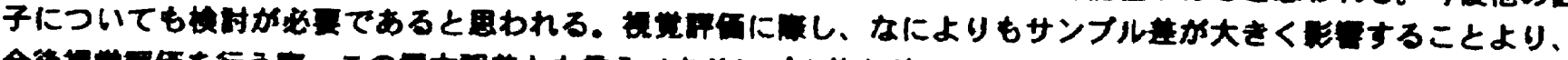

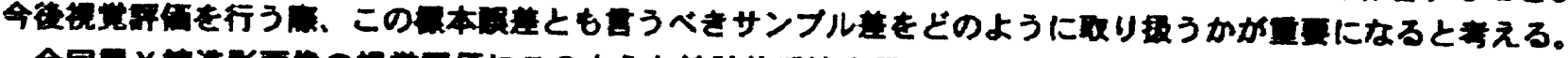

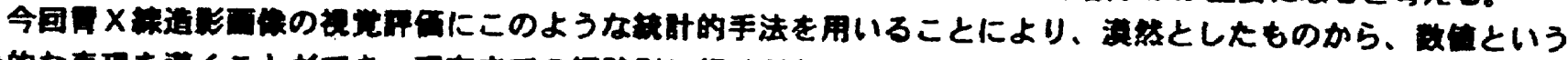

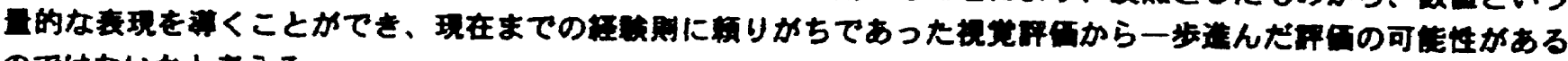
のではないかと言える。 